\title{
Da escrita ao toque: Elaborando experiências traumáticas com tutores de resiliência
}

\section{From writing to touching: Elaborating traumatic experiences with tutors of resilience}

\section{De la escritura al tacto: Elaborando experiencias traumáticas con tutores de resiliencia}

\section{Arthur Teixeira Pereira*}

Universidade do Estado do Rio de Janeiro - UERJ, Rio de Janeiro, Rio de Janeiro, Brasil

\section{Edna Lúcia Tinoco Ponciano**}

Universidade do Estado do Rio de Janeiro - UERJ, Rio de Janeiro, Rio de Janeiro, Brasil

Smith, R., Halfon, L., Malkovich, J. (Produtores), \& Chbosky, S. (Diretor). (2012). As vantagens de ser invisível [DVD]. São Paulo: Paris Filmes.

Uma discussão sobre o processo de desenvolvimento de um introvertido na adolescência pode ser elaborada a partir do filme $A s$ vantagens de ser invisível, destacando-se fatores como a relação interpessoal e a prática da escrita na elaboração de experiências traumáticas. O protagonista Charlie (Logan Lerman) apresenta traumas no seu desenvolvimento, indicando uma trajetória de sofrimento e elaboração de experiências traumáticas, com a participação, principalmente, dos amigos, de um professor, de uma médica e da escrita. São pessoas que representam formas de tutoria/cuidado que facilitam as respostas resilientes (Cyrulnik, 2015), cuja essência define-se pelo "relacionamento progressivo e constante com um 'outro significativo' que apoia e ativa a iniciação de processos de resiliência naquele que enfrenta a dor e o trauma" (Yunes, Fernandes, \& Weschenfelder, 2018, p. 85), impulsionando fatores de proteção e fortalecendo recursos como o da escrita.

$\mathrm{Na}$ escola, Charlie conhece Sam (Emma Watson) e Patrick (Ezra Miller). Cada um, a seu modo, atravessa problemas específicos. Embora Sam seja introduzida como uma jovem comunicativa e popular, revela, após aproximar-se de Charlie, vivências de relacionamentos abusivos, atravessados por suas relações familiares. 
Sam desperta em Charlie um interesse amoroso quase imediato. Patrick, por sua vez, é extrovertido, desafiador e enfrenta problemas com a expressão de sua homossexualidade.

A solidão é a primeira característica marcante de Charlie (Izbicki, Brandão, Carvalho \& Melo, 2015), ao relatar, em uma carta, ter interagido somente com sua família nas férias. Quanto ao início das aulas, escreve: "Só espero que eu faça um amigo". Isto demarca a dificuldade do jovem de se relacionar com as pessoas ao redor, além de revelar a principal forma de elaboração de suas emoções - a escrita -, pois é por meio das cartas que ele narra suas experiências. A escrita pode servir como meio de expressar as emoções, permitindo ao adolescente a construção de um lugar próprio, além de se reconhecer nele (Freitas \& Silva, 2014). Desse modo, a solidão pode ser positivada como forma de consciência e de diálogo interno sobre seus problemas. Todavia, Charlie apresenta retraimento social, fenômeno com diferentes faces, dentre elas, a timidez (Nunes, Faraco, \& Vieira, 2012), evidente em diversas cenas do filme que apresentam Charlie isolado, sem se comunicar com os demais alunos. Esse padrão é deslocado quando conhece Patrick. Ainda que sofra bullying e rejeição devido à homossexualidade, Patrick se relaciona amorosamente com Brad (Johnny Simmons), que não assume o relacionamento. Charlie se aproxima de Patrick, vivenciando uma relação de intimidade e de aceitação entre amigos, que permite a ambos a reafirmação de si, a inserção em um grupo e a consolidação da orientação sexual. O retraimento da sexualidade é comum em adolescentes homossexuais, devido aos conflitos enfrentados pelo medo de sofrer preconceitos e não ser aceito, tornando a revelação da identidade sexual um desafio (Costa, Machado, \& Wagner, 2015; Mata, Silva, Domingos, Jesus, \& Merighi, 2018), mas que é vivida com maior facilidade no encontro de amigos, tutores de resiliência. Outra relação importante é a com o professor de inglês, o Sr. Anderson (Paul Rudd), que se aproxima e estimula o aproveitamento de Charlie em sua disciplina, por meio da escrita, reforçando esse recurso.

A problemática dos relacionamentos abusivos está presente ao longo do filme em diferentes personagens. Além dos casos supracitados de Sam e Patrick, que é agredido por ser homossexual, há também a irmã de Charlie, Candace (Nina Dobrev), e sua tia Helen (Melanie Linskey), que também sofriam abusos e agressões de seus namorados. O filme mostra como as relações familiares afetam o desenvolvimento emocional dos(as) adolescentes, perpetuando um padrão de abuso e de violência (Ponciano \& Seild-de-Moura, 2016).

Quando Sam e Charlie compartilham um momento afetivo íntimo, em que Sam acaricia a perna dele, algo do passado de Charlie desperta. Esse toque (carinhoso/sexual) ressoa em todo seu corpo e revive a lembrança dos gestos sexualmente abusivos de sua tia Helen, 
durante sua infância, e ele rememora o que ocorreu durante a convivência com sua tia, demonstrando ter dissociado essa experiência, até então (Harris et al., 2016). Somando-se ao fato de se sentir muito só, com a ida de seus amigos à universidade, Charlie entra em estado de choque e passa a se culpar pela morte da tia, andando sem rumo pela casa e com os pensamentos desorganizados, retomados pelo trauma do abuso. Assim, ele é internado, até conseguir reelaborar todas as memórias em uma conversa com a Dra. Burton (Joan Cusack), outro tutor de resiliência. Após receber alta, Charlie consegue se recolocar na vida, descrevendo que se sente mais preparado para o novo ano letivo; ademais, passa a se comunicar melhor com seus familiares e a disfrutar mais dos momentos com os amigos, demonstrando ter elaborado as experiências vividas.

O filme exibe com leveza e complexidade o desenvolvimento de um adolescente tímido, cujo modo de ser e apreender o mundo vão se transformando ao construir novas relações. Pode-se considerar, a partir da história de Charlie, como o contato com outras pessoas e realidades pode impactar o desenvolvimento e a saúde mental de adolescentes, instrumentalizando-os no enfrentamento de experiências traumáticas, com a ajuda da escrita e de tutores de resiliência. A relação interpessoal é um elemento importante para a compreensão dos processos de desenvolvimento do(a) adolescente. Com ajuda da escrita, uma ferramenta com efeitos terapêuticos, a consciência e elaboração de emoções e de experiências traumáticas tornam-se abordáveis, de modo a diminuir a dissociação, conforme apresentado por Charlie. A partir de vários "toques", que recebe na interação com tutores de resiliência, e ao utilizar a escrita como forma de elaboração, um adolescente pode se transformar positivamente. Tendo no filme um exemplo, trata-se de uma articulação importante, à medida que é um campo de estudo pouco explorado, embora a escrita seja utilizada como uma ferramenta terapêutica (Pennebaker \& Evans, 2014). Por fim, enfatizamos que a articulação entre relações interpessoais e escrita constitui um campo promissor para mais investigações empíricas que embasem intervenções com adolescentes, que podem ser utilizadas na prática clínica.

\section{Referências}

Costa, C. B., Machado, M. R., \& Wagner, M. F. (2015). Percepções do homossexual masculino: Sociedade, família e amizades. Temas em Psicologia, 23(3), 777-788. doi:10.9788/TP2015.3-20

Cyrulnik, B. (2015). Resiliência: Como tirar leite de pedra. São Paulo: Casa do Psicólogo. 
Freitas, E. A. R., \& Silva, L. C. A. (2014). Escritas de si mesmo: Os adolescentes e seus blogs. Psicologia Clínica, 26(2), 139-157. Recuperado de http://www.scielo.br/scielo.php?script=sci_arttext\&pid=S010356652014000200009\&Ing=en\&tIng=pt

Harris, L. S., Block, S. D., Ogle, C. M., Goodman, G. S., Augusti, E. M., Larson, R. P., \& Urquiza, A. (2016). Coping style and memory specificity in adolescents and adults with histories of child sexual abuse. Memory, 24(8), 1078-1090. doi:10.1080/09658211.2015.1068812

Izbicki, S., Brandão, L. C., Carvalho, L. M., \& Melo, M. H. S. (2015). Rejeição entre pares - diálogo com o filme The Perks of Being a Wall flower. Estudos e Pesquisas em Psicologia, 15(2), 764-783. doi:10.12957/epp.2015.17711

Mata, N. D. S., Silva, M.H., Domingos, S. R. F., Jesus, M. C. P., \& Merighi, M. A. B. (2018). Homosexual adolescents and their relations with relatives: a phenomenological study. Online Brazilian Journal of Nursing, 16(4), 409-419. doi: 10.17665/1676-4285.20175845

Nunes, S. A. N., Faraco, A. M., \& Vieira, M. L. (2012). Correlatos e consequências do retraimento social na infância. Arquivos Brasileiros de Psicologia, 64(1), 122-138. Recuperado em 02 de outubro de 2018, de http://pepsic.bvsalud.org/scielo.php?script=sci_arttext\&pid=S1 809-52672012000100010\&lng=pt\&tIng=pt

Pennebaker, J. W., \& Evans, J. F. (2014). Expressive writings: Words that heal. Washington: Idyll Arbor.

Ponciano, E. L. T., \& Seild-de-Moura, M. L. (2016). Quem quer crescer? Relacionamento pais e filhos(as) da adolescência para a vida adulta. Curitiba: CRV Editora.

Yunes, M. A. M., Fernandes, G., \& Weschenfelder, G. V. (2018). Intervenções psicoeducacionais positivas para promoção de resiliência: O profissional da educação como tutor de desenvolvimento. Educação (Porto Alegre), 41(1), 83-92. doi:10.15448/1981-2582.2018.1.29766

\section{Endereço para correspondência \\ Arthur Teixeira Pereira}

Rua Dário Marques, lote 34, Jardim Metrópole, CEP 25575-060, São João de Meriti RJ, Brasil

Endereço eletrônico: arthurtp11.2009@gmail.com

\section{Edna Lúcia Tinoco Ponciano}

Rua Nogueira da Gama, 35/203, São Cristóvão, CEP 20910-150, Rio de Janeiro RJ, Brasil

Endereço eletrônico: ednaponciano@uol.com.br 
Recebido em: 30/10/2018

Reformulado em: 27/08/2019

Aceito em: 28/08/2019

\section{Notas}

* Graduando de Psicologia na Universidade do Estado do Rio de Janeiro.

** Professora Adjunta do Instituto de Psicologia na Universidade do Estado do Rio de Janeiro e do Programa de Pós-graduação em Psicologia Social da Uerj.

Este artigo de revista Estudos e Pesquisas em Psicologia é licenciado sob uma Licença Creative Commons Atribuição-Não Comercial 3.0 Não Adaptada. 